\title{
A EVOLUÇÃO DA CANOA MONÓXILA EM PERNAMBUCO, BRASIL (SÉCULOS XVI ao XX)
}

\author{
Carlos Celestino Rios e Souza ${ }^{1}$ \\ cccrios@hotmail.com \\ Hamilton Marcelo Morais Lins Júnior ${ }^{2}$ \\ marcelolinz@msn.com
}

\section{RESUMO}

A canoa monóxila, popularmente conhecida como canoa de um pau só, é uma embarcação utilizada pelos indígenas do Brasil desde antes da chegada dos primeiros navegantes portugueses no século XVI. Apesar do crescente desenvolvimento tecnológico ocorrido em Pernambuco ao longo dos últimos cinco séculos, a canoa foi objeto de uma série de modificações adaptativas. O presente trabalho procura explicar a evolução da tecnologia da canoa monóxila, relacionando as transformações e os acréscimos introduzidos no casco monóxilo e as variáveis ambientais, socioeconômicas e históricas entre os séculos XVI e XX. O presente artigo se mostra relevante diante da inexistência de trabalhos de cunho acadêmico que versem sobre a tecnologia das embarcações tradicionais de Pernambuco, cuja primeira datação de um artefato náutico é anterior ao descobrimento do Brasil.

Palavras-chave: Arqueologia Marítima, Canoa monóxila, Datação.

\footnotetext{
${ }^{1}$ Docente do Departamento de Arqueologia da UFPE.

${ }^{2}$ Discente do Programa de Pós-graduação em Arqueologia da UFPE.
} 


\begin{abstract}
The dugout canoe, popularly known as "canoa de um pau só", is a boat used by the natives of Brazil since before the arrival of the first Portuguese navigators in the 16th century. Despite the growing technological development occurred in Pernambuco over the past five centuries, the canoe was subjected to many adaptive changes. This paper seeks to explain the evolution of the dugout canoe's technology, relating the changes and additions introduced upon its hull with the environmental, socioeconomic and historical variables from the sixteenth to the twentieth century. This article is relevant, given the lack of academic works about the technology of traditional boats of Pernambuco and for obtaining the first dating from a nautical artifact prior to the discovery of Brazil.
\end{abstract}

Key Words: Maritime Archaeology, Dugout Canoe, Dating.

\title{
ARQUEOLOGIA MARÍTIMA
}

Desde o momento em que o homem fez uso de um tronco flutuante para aventurar-se sobre as águas de um lago, rio ou mar, novos horizontes se abriram para o proveito da humanidade. Os ambientes aquáticos, que, até então, se apresentavam como obstáculos e fonte limitada de recursos, passaram a ser utilizados como vias de deslocamento e de obtenção de novos recursos naturais.

Ao longo dos séculos, o homem aprimorou sua relação e seu conhecimento do ambiente aquático. Para McGrail (2014), a Arqueologia Marítima estuda essa relação entre o homem e o universo aquático (rios, lagos, mares e oceanos), abrangendo desde fundeadouros, trapiches, portos e estruturas relacionados à navegação a embarcações, seus usos e cargas.

A Arqueologia Naval é um ramo especializado da Arqueologia Marítima voltado para o estudo da tecnologia, a construção, a operação e os apetrechos empregados nas embarcações; seu objeto de estudo são os "navios e embarcações das épocas 
passadas, de todos os tipos, de todos os domínios e de todas as origens, sob seus diversos aspectos, técnico, funcional e social" (POMEY e RIETH, 2005; p. 10, tradução nossa).

Para atingir seus objetivos, a Arqueologia Naval recorre a documentações históricas, etnográficas, icnográficas e, sobretudo, aos vestígios materiais trazidos à tona pelas pesquisas arqueológicas, principalmente pela Arqueologia Subaquática.

\section{A embarcação como objeto de estudo}

"Em qualquer sociedade pré-industrial, desde o Paleolítico Superior ao século XIX, o barco (e posteriormente o navio) era a maior e mais complexa máquina produzida" (MUCKELROY, 1978, p. 3; tradução nossa). Para Frederick M. Hocker seria "a forma mais perfeita de tecnologia portátil das sociedades préindustriais" (2004, p. 4, tradução nossa).

Para Muckelroy um navio, ou qualquer embarcação, seria: "1. Uma máquina concebida para utilizar uma fonte de energia com o objetivo de servir como meio de transporte; 2. Uma unidade funcional de um sistema econômico ou militar, em sua razão de ser; 3. Comunidade com hierarquia, costumes e convenções próprias" (1978, p. 216, tradução nossa).

Para Pomey e Rieth (2005), uma embarcação é uma estrutura arquitetônica cuja flutuabilidade foi atingida de forma artificial, através do emprego de materiais e 
técnicas que provêm de um casco estanque. Diferencia-se de um edifício, estrutura arquitetônica fixa, por sua capacidade de se locomover de forma controlada, aparelhada com sistemas de propulsão e governo que funcionam dentro de princípios estritamente mecânicos. Já sua "razão de ser" reside na sua inserção como unidade funcional de um sistema econômico ou militar:

Uma embarcação, grande ou pequena, pré-histórica ou moderna, concebida e construída como instrumento adaptado a determinada(s)função(ões), em resposta às necessidades específicas de ordem econômica; transporte de mercadorias, pessoas, para a pesca ou militar (defesa ou ataque). Estas funções apresentam-se arquitetonicamente de diferentes maneiras (2005, p. 17, tradução nossa).

Até o século XVI, embarcações eram artefatos produzidos empiricamente através de sequências de tentativas e erros, observação e experimentação, ajustadas e melhoradas até se atingirem o desenho e a forma adequada às necessidades do grupo humano e ao meio navegável.

\section{TECNOLOGIA DA CANOA MONÓXILA}

Para o Almirante Alves Câmara, um dos primeiros a estudar as embarcações tradicionais e indígenas do Brasil, a canoa é a evolução natural do primeiro e mais rudimentar instrumento utilizado pelo homem para navegar sobre as águas, o tronco de uma árvore (ALVES CÂMARA, 1937).

Para McGrail (2014), as canoas monóxilas são, essencialmente, troncos de árvore escavados pelo processo de redução, caracterizando-se pela subtração de matéria- 
prima e modelagem até que se atinja a forma de uma embarcação. Sua construção abarca uma série de processos e técnicas que formam uma cadeia operatória, conforme quadro a seguir:

1. Escolha da árvore adequada de acordo com sua característica (lenheira, com poucos defeitos, madeira leve, resistente à água e aos organismos xilófagos) e tipo de emprego da embarcação desejada.

2. Limpeza e preparação do local onde a árvore deve tombar e onde serão realizados os primeiros trabalhos de limpeza e modelagem do tronco.

3. Retirada de galhos, da copa e delimitação do tronco-base.

4. Escolha do lado a ser escavado, primeiro esboço, definição do desenho das extremidades (proa e popa) e início do processo de redução do tronco.

5. Transporte, quando necessário, do casco inacabado para o estaleiro, usualmente situado na proximidade de um corpo d'água, onde se concluirá a confecção.

6. Processo de redução do tronco em casco através de escavação do espaço interno e modelagem da parte externa e das extremidades.

7. Inserção, quando necessário, dos elementos justapostos ou dos sistemas de propulsão e governo.

8. Lançamento e navegação.

Quadro 1: Etapas de produção de uma canoa monóxila. Os autores, 2016.

As técnicas de ferramentas empregadas na produção de uma canoa monóxila variam de acordo com a época, o local, o momento histórico, as tradições e o ferramental disponível aos grupos que as produziram.

\section{Evolução da canoa monóxila dos séculos XVI a XX}

$\mathrm{O}$ trabalho teve como objetivo principal estudar as mudanças e os acréscimos sofridos pela arquitetura da canoa monóxila nos cinco séculos que se seguiram à chegada dos europeus ao Novo Mundo. 
A hipótese levantada é que as canoas monóxilas sofreram modificações tanto no seu desenho quanto em sua estrutura arquitetônica. Tais mudanças foram determinadas por novos contextos e usos impostos à canoa monóxila diante das transformações ocorridas na sociedade brasileira ao longo dos últimos 500 anos. Além de uma interpretação evolutiva, buscou-se entender o significado de tais transformações, em termos dos novos elementos arquitetônicos e tecnológicos, como resposta às necessidades cotidianas dos grupos humanos, dentro dos diversos contextos históricos e socioeconômicos.

Definir como seria a canoa monóxila anterior ou quando da chegada dos primeiros europeus no século XVI é o primeiro passo para se estudar e entender as modificações sofridas por esse tipo de embarcação nos séculos que se seguiram. $\mathrm{O}$ modelo-base foi construído a partir dos relatos etno-históricos de viajantes e exploradores, encontrados na canoa Extremoz 04, cuja datação $700 \pm 30$ anos BPafaz pouco mais de um século anterior à chegada dos primeiros europeus. Ela é uma canoa monóxila com características primitivas, descoberta em 1997 na Lagoa de Extremoz ${ }^{3}$, Rio Grande do Norte.

Essa canoa integra, atualmente, o acervo do Museu Câmara Cascudo, em Natal, RN. Na Tabela 1, observam-se as datações por $\mathrm{C}^{14}$ da canoa Extremoz 04, assim como de outros exemplares achados na mesma lagoa ao longo das décadas de 1990 e 2000. Durante a pesquisa foram recolhidas amostras da madeira dessas canoas,

\footnotetext{
${ }^{3}$ Lagoa de Extremoz: localizada a $16 \mathrm{~km}$ da cidade de Natal $\left(05^{\circ} 42\right.$ '20" S e $\left.035^{\circ} 18^{\prime} 26^{\prime \prime} \mathrm{W}\right)$, com capacidade de 11 milhões de $\mathrm{m}^{3}$, área de $4,2 \mathrm{~km}^{2}$, profundidade média de $4 \mathrm{~m}$; como afluentes tem o Rio Guajiru, no extremo sul, e o Rio Doce, ao norte (JERÔNIMO e SOUZA, 2013).
} 
com o objetivo de tentar identificar a matéria-prima utilizada e estabelecer sua datação.

\begin{tabular}{|l|c|l|}
\hline Canoa & Idade e desvio-padrão & \multicolumn{1}{|c|}{ Idade calibrada } \\
\hline Extremoz04 & $700 \pm 30 \mathrm{BP}$ & $1290-1320 \mathrm{e} 1350-1385 \mathrm{DC}$ \\
\hline Extremoz 03 & $280 \pm 30 \mathrm{BP}$ & $1640-1665 \mathrm{DC}$ \\
\hline Extremoz 01 & $270 \pm 30 \mathrm{BP}$ & $1645-1665 \mathrm{DC}$ \\
\hline Extremoz 02 & $210 \pm 30 \mathrm{BP}$ & $1665-1685$ e $1730-1805 \mathrm{DC}$ \\
\hline
\end{tabular}

Tabela 1 - Intervalos cronológicos determinados pelo método do $\mathrm{C}^{14}$ para canoa Extremoz 04. Fonte: Beta Analitic, 2014.

\section{A canoa monóxila pré-histórica}

Em fins do século XV e princípio do XVI, os indígenas nativos do Brasil encontravam-se ainda no estágio Neolítico primário pré-urbano, tendo as ferramentas de pedra como a base de seu instrumental tecnológico (MARTIN 1999). Dentro de tal arcabouço tecnológico, tais grupos foram capazes de produzir certa variedade de embarcações: jangadas, canoas de juncos, de casca de árvores e as monóxilas (CAMINHA, 1500 apud AMADO, 2001; SOUZA, 2000).

Essas embarcações eram empregadas, majoritariamente, em atividades cotidianas de caça, pesca, deslocamentos e, esporadicamente, nas expedições de guerra, tanto ao longo da costa quanto das bacias hidrográficas do País.

As canoas monóxilas pré-cabralinas se enquadrariam no tipo XA da classificação de Arnold (1996), uma embarcação exclusivamente monóxila sem acréscimo de

\footnotetext{
${ }^{4} \mathrm{O}$ desvio-padrão admite uma probabilidade de $68 \%$ de que a idade real se encontra nos intervalos mencionados na tabela.
} 
elementos construtivos. Casco em U; fundo chato; bojo arredondado ou reto; bordos cilíndricos ou retos com espaço interno livre. Propulsão a remo ou vara ativada pela força motora humana dos remadores.

Nas extremidades, pouca ou nenhuma diferença entre proa e popa, facilitando o varar terra ${ }^{5}$ e sair sem precisar virar a canoa, mudando apenas a posição dos remadores; essas extremidades apresentam perfil longitudinal em reta oblíqua pouco lançada e pouco elevada em relação aos bordos laterais; de forma externa obtusa ou bico largo reto.

Em termos funcionais apresentavam-se em dois tipos: as menores, para as atividades cotidianas da pesca e os pequenos deslocamentos, navegavam de preferência em águas tranquilas ou próximas à costa, com ventos de até força 1. Já as canoas de guerra poderiam atingir até $30 \mathrm{~m}$ de comprimento, com boca de $1 \mathrm{~m}$. Excetuando-se as dimensões, ambos os tipos eram arquitetonicamente idênticos (ALDAZABAL e AGUEDA CASTRO, 2000).

\section{A canoa monóxila no século XVI}

Em abril de 1500, Caminha reconheceu, no litoral do atual Estado da Bahia, algumas canoas indígenas de um só tronco, as quais comparou às "almadias", já familiares aos portugueses desde o século XV, nas costas da África e nos mares da Ásia (AMADO, 2001; CASCUDO, 2002). Já o vocábulo canoa era utilizado pelos povos aruaques das Antilhas para se referirem aos seus barcos monóxilos,

\footnotetext{
${ }^{5}$ Colocar a embarcação em seco, em varadouro, ou seja, na areia da praia (CHERQUES, 1999).
} 
bem como aparece citado pela primeira vez em carta datada de 15 de fevereiro de 1493.

Para Barbara Purdy, as ferramentas de metal foram a principal modificação introduzida pelo colonizador europeu no processo de produção da canoa monóxila:

"Enquanto as ferramentas para o trabalho em madeira mudaram com a chegada dos europeus e de suas ferramentas de ferro, os métodos de construção das canoas monóxilas permaneceram basicamente o mesmo ainda no período histórico" (PURDY, 1991 apud HARTMANN, 1996; p. 29).

A permanência da canoa monóxila como elemento da cultura indígena no Brasil colônia (MELLO, 1978) está na sua capacidade de superar, em razão do seu pouco calado, a pouca profundidade dos rios litorâneos;de manobrar com facilidade em locais estreitos; e a abundância de matéria-prima para sua produção.

No primeiro século da colonização, as embarcações indígenas foram largamente utilizadas pelos colonizadores para explorar as novas terras, tendo os rios com principais vias para acessar o interior ainda inexplorado, além de abastecer e escoar a produção dos primeiros núcleos coloniais fixados na região litorânea. Abaixo o desenho de uma canoa daquele período. 

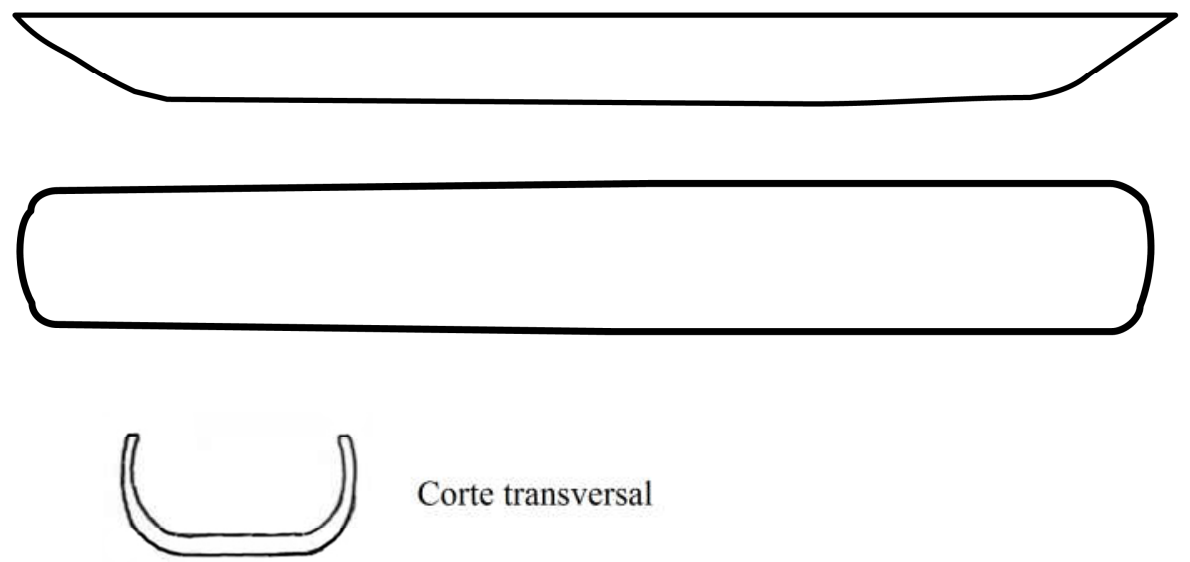

Corte transversal

Figura 1: Desenho esquemático da canoa monóxila pré-cabralina e utilizada ainda no século XVI.

\section{A canoa monóxila no século XVII}

No século XVII,uma vez consolidada a colônia como fornecedora de matériasprimas e especiarias tropicais dentro do sistema mercantilista mundial,foram introduzidas as primeiras modificações sobre a estrutura arquitetônica do casco monóxilo. Com destaque para a cana-de-açúcar no Nordeste, em Pernambuco, naquele início de século, havia 99 engenhos de açúcar em pleno funcionamento (MORENO, 1955).

Nesse contexto, as vias aquáticas foram largamente empregadas no abastecimento e escoamento da produção, em um Brasil de caminhos terrestres precários ou mesmo inexistentes, cuja resistência indígena ainda não havia sido superada. 
Foram as novas funções assumidas pelas canoas no transporte de cargas e/ou pessoas e no abastecimento e escoamento da produção colonial que levaram a modificações em seu desenho e sua estrutura arquitetônica. A mais notável, as costelas em reserva, que aumentavam a resistência do casco monóxilo, permitindo um aumento substancial na capacidade de carga das canoas e dispensando o emprego de cavilhas na construção da embarcação.

Na canoa Extremoz 03, as costelas em reserva deixadas por ante a ré da proa e por ante a vante da popa dividem, nitidamente, a embarcação em três setores: proa, corpo central e popa, ocupando, a porção intermediária, quase todo o comprimento da canoa, delimitando espaço reservado para a carga, o que facilitava a acomodação e o controle do volume embarcado.

Outra modificação foi a introdução do banco de popa em reserva, que marca a mudança na forma de organização e de propulsão na canoa monóxila. Se nas canoas indígenas a propulsão era feita por remadores postados em pé, sentados ou ajoelhados no fundo do casco e, normalmente, todas as pessoas embarcadas contribuíam com o esforço propulsor; o método europeu dava prioridade ao remador sentado em banco. Além dessa diferença cultural, o transportar carga e mercadorias levava a uma diminuição no número de remadores, com um maior esforço físico sobre os remadores remanescentes, cuja fadiga era, entretanto, aliviada pela postura de remar sentado. 
A mudança aconteceu também no desenho das extremidades, com uma maior diferenciação entre proa e popa, sendo a proa um pouco mais lançada, em concha; com forma em ogiva. Essa nova configuração da proa propicia à canoa uma melhor hidrodinâmica, facilitando o seu deslocamento no meio líquido, refletindo em um aumento na velocidade ou mesmo permitindo um pequeno aumento de carga sem agravar o esforço físico imposto ao condutor. Desse modo a canoa desse século manteve-se dentro da tipologia XA, sem a presença de elementos justapostos, conforme a Figura 2.
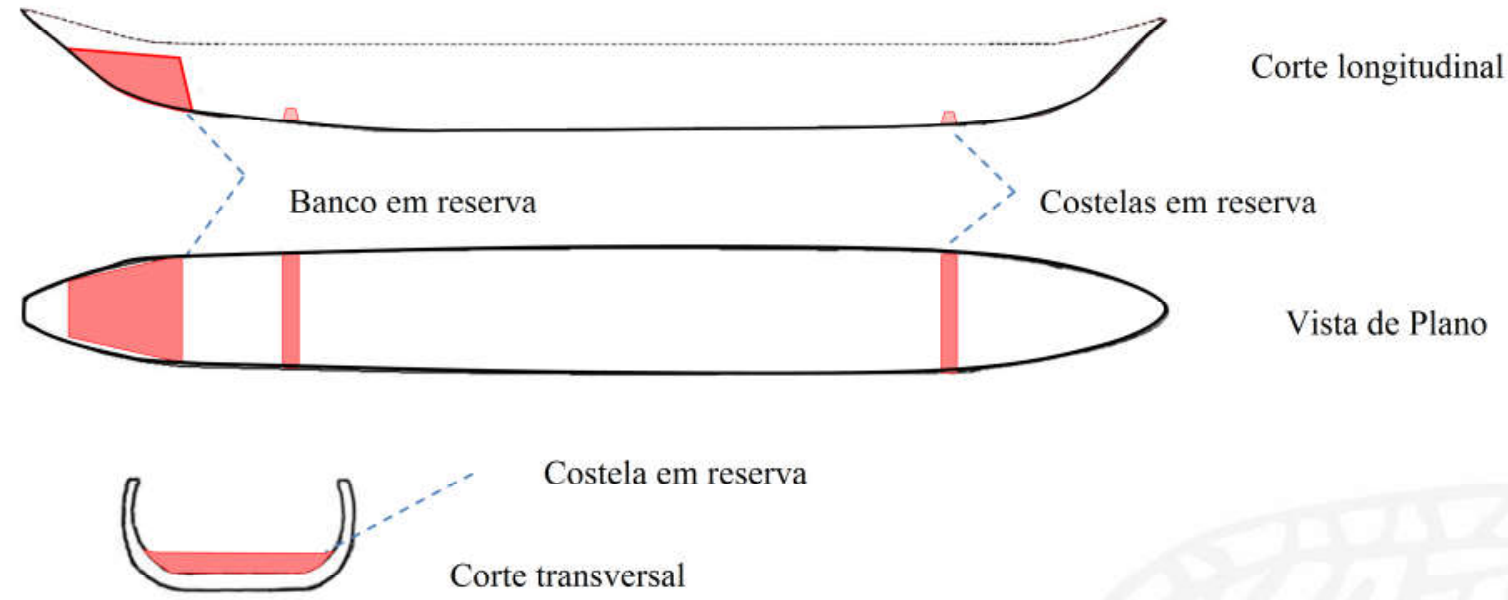

Figura 2: Desenho esquemático da canoa monóxila do século XVII, destacando as mudanças introduzidas (em vermelho) e o novo desenho das extremidades.

\section{A canoa monóxila no século XVIII}

Em tal canoa o banco de popa e a costela em reserva foram substituídos por elementos justapostos sobre a estrutura do casco. Modificando a tipologia da embarcação, agora classificada no tipo XB, apresenta elementos arquitetônicos 
considerados menores e que não interferem na capacidade de flutuação da embarcação (ARNOLD, 1996).

No lugar do banco de popa em reserva, introduziu-se um banco em madeira ou mesmo uma plataforma presa ao casco ou sobreposta aos bordos laterais. Essa estrutura, além de servir como banco, poderia ser utilizada como plataforma na propulsão com vara, quando o condutor, em pé, poderia impulsionar a canoa e manter a visada livre, por cima da carga acomodada na parte central da embarcação.

O uso da vara como forma de propulsão só é possível na navegação com pouca profundidade, já que o condutor precisa apoiar uma das extremidades da mesma sobre o leito firme para transmitir a força motora à embarcação.

Sobre as extremidades, alguns exemplares receberam os acréscimos de guirlandas ou cangalhas (ALVES CÂMARA, 1937). Estas seriam peças colocadas sobre os bordos da proa ou da popa, ou em ambas, para elevar sua altura, protegendo os passageiros e a carga do spray de água gerado pelo deslocamento da canoa. Essas canoas se enquadrariam no tipo $\mathrm{XC}$, em que há a elevação da base monóxila (ARNOLD, 1996).

O século XVIII foi marcado pelo crescimento urbano dos antigos núcleos coloniais. Cidades como Recife, Salvador e Rio de Janeiro passaram a apresentar uma efervescente atividade urbana, concomitante com o movimento portuário. As 
necessidades de tais centros foram largamente supridas pelo transporte por hidrovias. Através delas era transportado material de construção, lenha, capim, água, pescados e os mais variados tipos de produtos para abastecer as cidades.

Em Pernambuco as vias hídricas continuaram a desempenhar um importante papel, não somente no abastecimento do Recife, mas na comunicação entre os diversos povoados situados ao longo da costa e dos rios, no escoamento da produção açucareira e no abastecimento dos engenhos. Nesse quesito a canoa desempenhou um papel importante, principalmente por sua capacidade de navegar com pouco calado, atingindo locais e portos onde embarcações maiores não podiam chegar.

Nos engenhos a canoa era o meio de transporte responsável pelo fornecimento de pescados, assim como pelo abastecimento de lenhas para suas fornalhas. Como salientou Antonil no início do século, um engenho precisava ter a seu serviço, além das coisas ligadas ao cultivo e fábrica, um certo quantitativo de barqueiros, canoeiros, calafates, carapinas.

Além do abastecimento de víveres e vitualhas, "há mister dois barcos velejados para se buscar nos portos, indo um atrás do outro sem parar" para manterem alimentadas as fornalhas de lenha durante os sete ou oito meses da moagem (ANTONIL, 1969; p. 2). Abaixo o desenho de uma canoa do século XVIII. 


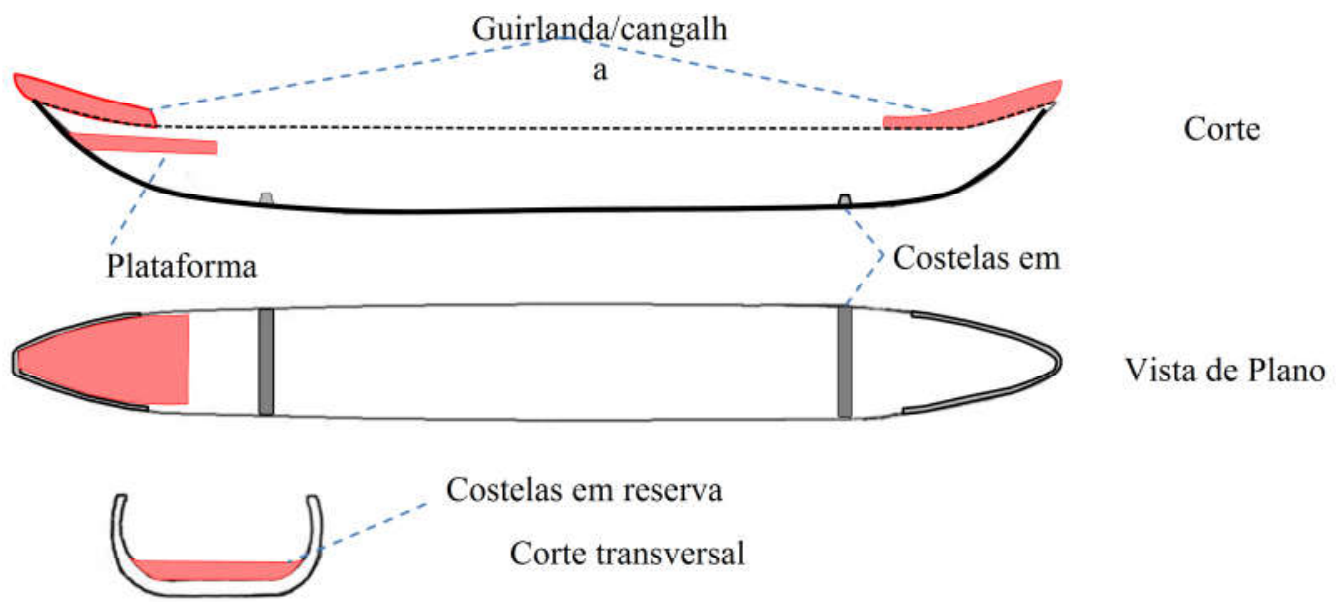

Figura 3: Desenho esquemático da canoa monóxila do século XVIII, destacando as mudanças introduzidas (em vermelho).

\section{A canoa monóxila no século XIX}

Foi nesse século que a canoa monóxila sofreu as maiores transformações. Até então era empregada normalmente em águas abrigadas, sendo a navegação costeira realizada apenas em condições de mar muito favoráveis, com ventos fracos e poucas ondas, até força 2 na escala de Beaufort.

Foi a partir da primeira metade do século que passou a navegar com maior frequência ao longo da costa, chegando a desempenhar um importante papel no transporte de passageiros e mercadorias, ligando os núcleos habitacionais costeiros e, através das bacias hidrográficas litorâneas, as zonas canavieiras ao Porto do Recife. Os embonos e a vela foram os principais responsáveis por tal mudança. 
O embono consistia em tronco de madeira leve, usualmente pau-de-jangada (Apeiba tibourbou), ou de outras madeiras flutuantes, como o mulungu (Erythrina mulungu) e a timbaúba (Enterolobium timbouva). Os embonos eram amarrados externamente aos bordos laterais, acima da linha-d'água. Aumentavam a flutuabilidade e estabilidade da canoa, permitindo que ela pudesse navegar com maior segurança ao longo da costa, em condições de vento força 3 na escala Beaufort.

Tirando proveito dos espaços e do regime de ventos encontrado no mar adjacente, as canoas monóxilas passaram a utilizar a força eólica como força propulsora e a vela como sistema de propulsão. Segundo Cascudo (2002), o uso da vela em pequenas embarcações, mormente nas jangadas, foi uma consequência do aumento da população branca no litoral ainda no século XVII.

Durante a ocupação batava do Nordeste, de 1630 a 1654, houve a introdução da bolina, artefato auxiliar necessário à navegação a vela. A bolina, empregada usualmente em pequenas embarcações sem quilha, é fundamental na navegação de través, diminuindo a deriva e mantendo o rumo desejado. Na sua ausência, o barco tende a girar sobre o eixo do leme, levando a proa a arribar e sair do rumo. Além disso, ela auxilia na estabilidade ao baixar o centro de gravidade da embarcação.

O uso da vela, assim como já havia ocorrido com as jangadas, exigiu a inserção de novas estruturas à sua arquitetura. Foi preciso acrescentar e adaptar ao casco todo 
o aparelhamento necessário para a inserção do mastro, manobras da vela e governo da embarcação, como a retranca usada na sustentação e abertura da vela, o cordame para a manobra e o recolhimento, além de outros elementos construtivos, como o banco de vela, a carlinga e as costelas, agregados à embarcação para sustentação do mastro, transmissão e distribuição da força exercida pelo vento sobre a área vélica.

Foi Kidder que proporcionou uma das melhores descrições desse tipo de canoa, durante a viagem que fez à Ilha de Itamaracá, em fins da década de 1830:

Construída de um único tronco [...] tinha nas extremidades dois pequenos tombadilhos. No meio, o barco era inteiramente aberto para receber carga. No mastro panejava enorme vela triangular, além da bujarrona. Dos lados pendiam embonos ou boias feitas de dois grandes troncos da madeira com que se fazem jangadas, atadas em conjunto e presas ao bordo superior do barco a fim de evitar que adernasse (KIDDER, 1972; p. 100).

A partir da segunda metade do século XIX, a introdução da malha ferroviária ligando as zonas produtoras de açúcar ao porto levou à diminuição da importância do transporte por via hídrica, principalmente nas bacias dos rios litorâneos. Canoas, barcaças, jangadas e outras pequenas embarcações ficaram restritas ao transporte de passageiros e pequenas mercadorias para os povoados costeiros e às atividades pesqueiras. Na Figura 4 a materialização do descrito. 

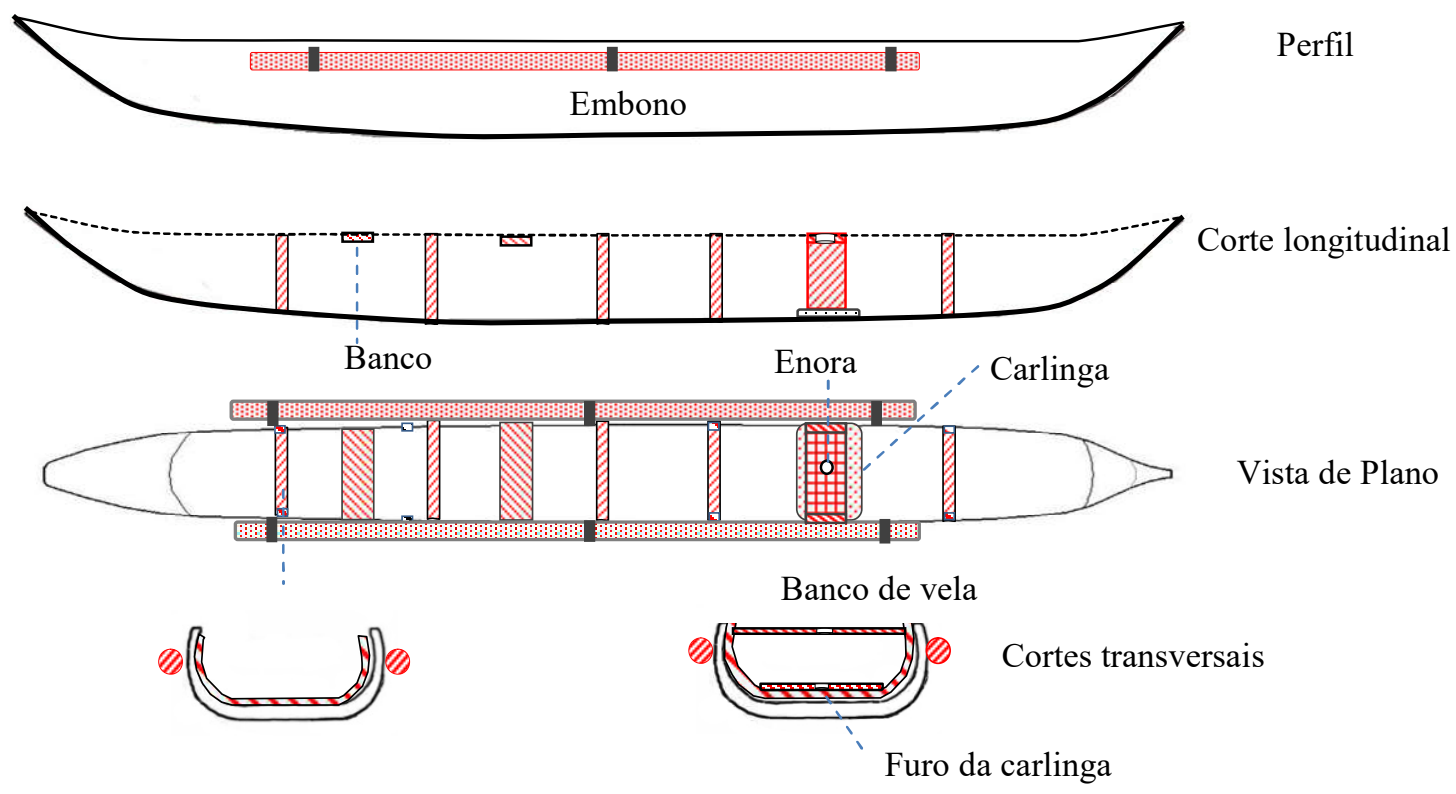

Figura 4: Desenho esquemático das modificações introduzidas na canoa monóxila no século XIX.

\section{A canoa monóxila no século $X X$}

$\mathrm{Na}$ primeira metade do século passado, a canoa monóxila estava restrita às atividades pesqueiras e ao transporte de pequenas mercadorias nos rios litorâneos e ao longo da costa. $\mathrm{O}$ aumento da malha rodoviária, principalmente a partir da década de 1930 (DNIT, 2014), foi, paulatinamente, acabando com a pequena cabotagem no litoral. No entanto, as canoas continuaram a ser empregadas no transporte de alguns tipos de mercadorias, como pescados, cal e coco, produzidos nos povoados costeiros e direcionados a abastecer os mercados das grandes cidades litorâneas, como o Recife. 
A inexistência de câmaras frigoríficas e de estradas confiáveis, que ligassem esses povoados aos grandes centros urbanos, tornava a canoa o meio mais rápido de fazer com que o pescado chegasse ainda fresco à mesa dos consumidores (LINS e GRANJA, 2008; LINS, 2007). Com a ampliação da malha viária litorânea durante as décadas de 1970 e 1980, as canoas monóxilas, assim como outras pequenas embarcações, ficaram restritas, principalmente, às atividades pesqueiras no mar adjacente e zonas estuarinas.

$\mathrm{Na}$ estrutura arquitetônica da canoa, a principal mudança notada foi o desaparecimento dos embonos. Alguns exemplares, no entanto, sofreram o acréscimo de guirlandas na proa e na popa e de uma tábua sobre os bordos laterais, aumentando a borda-livre em no máximo $15 \mathrm{~cm}$, visando compensar a perda dos embonos. Os demais elementos arquitetônicos se mantiveram, praticamente, imutáveis.

A partir das últimas décadas do século $\mathrm{XX}$, as políticas de proteção dos remanescentes da mata atlântica, que culminaram com o Decreto $\mathrm{n}^{0}$ 99.547, de 25 de setembro de 1990, proibindo toda e qualquer supressão de vegetação nativa, impediram o acesso dos carpinteiros navais à matéria-prima empregada nas canoas.

O uso de madeiras cortadas em tábuas levou ao surgimento das bateiras, embarcação de produção simples e rápida. Soma-se a isso, a evolução dos 
recursos tecnológicos, como emprego da fibra de vidro na construção dos cascos, que tornou a antiga e pesada canoa de um pau só obsoleta.

Durante as pesquisas, entre novembro de 2013 e março de 2014, foram realizadas prospecções no litoral pernambucano, desde a Barra de Sirinhaém (litoral sul) à praia de Catuama, Goiana, PE (litoral norte), resultando na localização de 17 exemplares de canoas monóxilas ainda remanescentes empregadas, majoritariamente, na pesca estuarina e costeira.

As tipologias identificadas foram XA ( $\mathrm{X}=$ Base monóxila obtida exclusivamente por redução; $\mathrm{A}=$ Ausência de elementos justapostos); $\mathrm{XB} \quad(\mathrm{B}=$ Elementos justapostos menores); e $\mathrm{XC}(\mathrm{C}=$ elevação da altura do casco monóxilo), o que demonstrou a permanência e coexistência de tipos variados. Na Figura 5 as modificações do século XX.

\section{CONCLUSÃO}

A canoa monóxila é um elemento do patrimônio naval brasileiro anterior à chegada dos primeiros europeus. Caracteriza-se como um artefato de navegação utilizado pelos povos autóctones. Foi um dos elementos da cultura indígena adotado e largamente utilizado pela sociedade colonial e por seus sucessores.

Ao longo dos últimos cinco séculos, a canoa monóxila evoluiu desde a canoa indígena às canoas remanescentes, em um processo de constante adaptação a novas funções, ligadas às mudanças no contexto socioeconômico e político 
operadas na sociedade brasileira ao longo da sua história. As modificações no desenho do casco, assim como a introdução de novos elementos construtivos, sistemas de propulsão e governo sobre a base monóxila, foram respostas a novos usos e necessidades dos grupos humanos que as produziram e utilizaram.

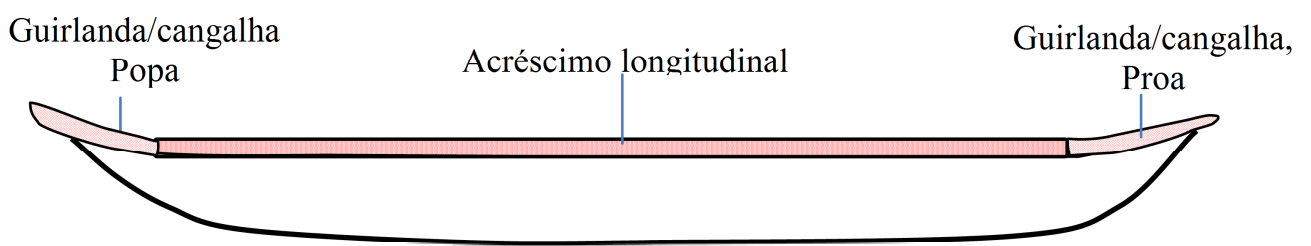

Perfil
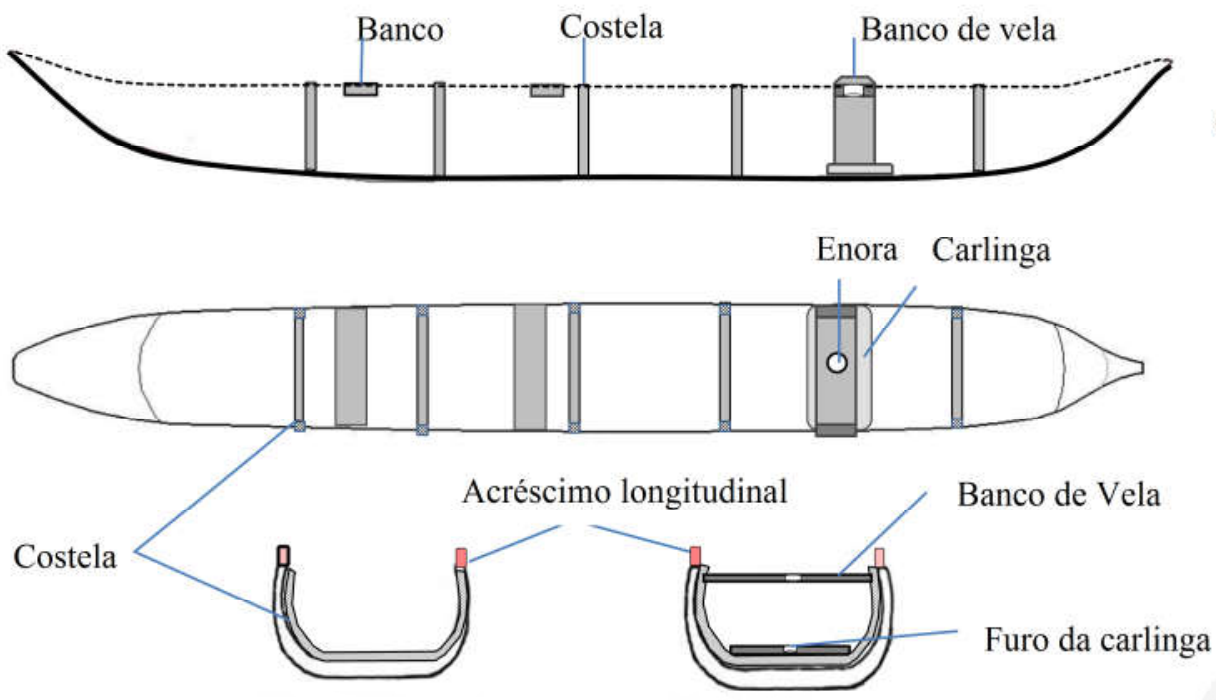

Vista de Plano

Figura 5: Desenho esquemático das modificações introduzidas na canoa monóxila no século XX. 
Sua obsolescência se deu diante da mudança na matriz de transporte e logística operada na região do litoral nordestino. Outros elementos podem ser elencados, também, em decorrência das leis ambientais de proteção dos remanescentes da mata atlântica. Reduziu-se, desse modo, o acesso à matéria-prima, bem como à introdução de novos materiais construtivos.

\section{REFERÊNCIAS BIBLIOGRÁFICAS}

ALDAZABAL, V. \& AGUEDA CASTRO, M. La construcción de canoas monoxilas en la cuenca del Plata. In Journal de la Société des Américanistes. Tomo 86, 2000.

ALVES CÂMARA, A. Ensaio Sobre as Construções Navais Indígenas do Brasil. São Paulo: Companhia Editora Nacional, 1937.

ALVES, F. J. S. A tradição monóxila náutica em Portugal e no Brasil - achegas para um debate sobre problemáticas comuns. In CAMPOS, J. B.; ZOCCHE, J. J.; CEREZER, J. F.; OOSTERBEEK, L. M. (Orgs.). Arqueologia Iberoamericana e Transatlântica: Arqueologia, Sociedade e Território: Erechim: Instituto Terra e Memória (ITM), Universidade do Extremo Sul Catarinense (UNESC), Habilis Editora, 2013.

AMADO, J. Brasil 1500: quarenta documentos. Brasília: Ed. Universidade de Brasília, São Paulo: Imp. Oficial do Estado de São Paulo, 2001.

ANTONIL, A. J. Cultura e Opulência do Brasil por suas Drogas e Minas. Recife: Museu do Açúcar, 1969.

Pirogues monoxyles d'Europe centrale: construction, typologie, évolution. Tomo 2. Neuchâtel: Musée Cantonal d'archéologie, (Archéologie neuchâteloise 21), 1996.

CASCUDO, L. C. Jangada: uma pesquisa etnográfica. 2a Ed., São Paulo: Global, 2002.

CHERQUES, S. Dicionário do mar. São Paulo: Globo, 1999.

DNIT, Histórico do Rodoviarismo. Disponível em: http://www1.dnit.gov.br/historico/. Acesso em: 06.12.2014.

HARTMANN, M. J. The Development of Watercraft in the Prehistoric Southeastern United States. College Station: o autor, 1996. 
HOCKER, F. M. "Shipbuilding: Philosophy, Practice, and Research" in HOCKER, F. M. e WARD, C. A. Philosophy of Shipbuilding: conceptual approaches to the study of wooden ships. Prefácio de George F. Bass, Texas A \& M University Press, 2004.

JERÔNIMO, C. E. M.; SOUZA, F. R. S. Determinação do índice de qualidade da água da lagoa de Extremoz - RN: série temporal e correlação a índices pluviométricos. In Revista Eletrônica em Gestão, Educação e Tecnologia Ambiental, v. 10, n 10, janeiro-abril, 2013.

KIDDER, D. P. Reminiscências de viagens e permanência no Brasil, compreendendo notícias históricas e geográficas e das diversas províncias. São Paulo: Livraria Martins, Editora da Universidade de São Paulo, 1972.

LINS, M. Mercados do Recife. Recife: O autor, 2007.

LINS, M.; GRANJA, R. Reconhecimento e Monitoramento de Embarcações Tradicionais-PE. Recife: IPHAN, 2008 (texto inédito).

MARTIN, G. Pré-história do Nordeste do Brasil. $3^{\text {a }}$ Ed. Recife: Editora Universitária UFPE, 1999.

MCGRAIL, S. Ancient Boats in North-West Europe: The Archaeology of Water Transport to Ad 1500. s.1.: Routledge, 2014.

MELLO, E. C. Canoas do Recife: em estudo de micro-história urbana. In Revista do Instituto Arqueológico, Histórico e Geográfico Pernambucano, v. L, Recife: Instituto Arqueológico, Histórico e Geográfico de Pernambuco, 1978.

MORENO, D. C. Livro que dá razão do Estado do Brasil. Recife: Comissão Organizadora e Executiva das Comemorações do Tricentenário da Restauração Pernambucana, Arquivo Público Estadual, 1955.

MUCKELROY, K. Maritime archaeology. London: Cambridge University Press, 1978.

POMEY, P.; RIETH, E. L’Archéologie Navale. Paris: Editions Errance, 2005.

SOUZA, G. S.Tratado descritivo do Brasil em 1587. Recife: Massangana, 2000. 